\title{
Impacts of community lay-leader health worker training and practice (Uttarakhand, India)
}

\author{
Nicole Butcher ${ }^{a}$, Nathan Grills ${ }^{b}$

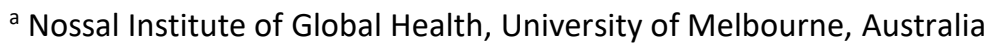 \\ ${ }^{b}$ MBBS, MPH, DPhil, Associate Professor and Public Health Physician, Nossal Institute of Global Health, University \\ of Melbourne, Australia
}

\begin{abstract}
This study investigated the impacts of the Community Lay-Leaders Health Training Certificate course on trainees and their communities in the state of Uttarakhand, North India. A suite of semi-structured interviews and focus group discussions were conducted among course stakeholders and graduates, respectively, and textual data was added to the data set. Thematic analysis of the results revealed four themes, including: (1) the effectiveness of course design and delivery, together with the key role of the coordinating facilitator; (2) the match between graduates' practices, the providing institution's objectives and general expectations of community health workers; (3) the strengthening of the health system through skills multiplication, collaboration with existing authorities, and advocacy for higher quality in professional practice; and (4) the need for ongoing support and training post-graduation. The findings are consistent with literature concerning community health workers' roles and challenges, although some potentially unique outcomes were noted with respect to the pastoral support provided to trainees and the pro-active transfer of graduates' knowledge and skills to fellow villagers.
\end{abstract}

Key words: community health worker, training, India, primary healthcare, advocacy, health system strengthening

\section{Introduction}

Community Health Workers (CHWs) provide and extend health education and healthcare to remote populations where geography and socio-economic disadvantage typically impede access to health information and services. Where CHWs operate, villagers can experience improved health outcomes. ${ }^{1}$ Acting as a link to formal healthcare services, CHWs also support or organise community development activities and data collection. ${ }^{2,3}$ Worldwide, the specifics of CHW programs and activities vary greatly, however, and the National Health Mission of India initiated an effective CHW program in 2008 to train villagers as Accredited Social Health Activists (ASHAs) to expand healthcare coverage. This program alone remains insufficient to meet the needs

July 2017. Christian Journal for Global Health 4(2):43-52. 
of the large Indian population in rural areas, and the work of ASHAs has for the most part been limited to maternal and child health. ${ }^{4}$

In view of the poor distribution of human resources for health in India's rural, tribal, and hill areas, the Christian Medical College (CMC) in Vellore, India, sought to enhance efforts to respond to the high burden of largely preventable and often easily treatable diseases by establishing the community lay-leaders health training certificate (CLHTC) course in 2011.4-6 The CLHTC course trains lay leaders with the knowledge, skills, and attitudes to serve their local villages and schools with health promotion, health education, and basic health care. The course takes an intentionally holistic approach to health and wellbeing by addressing spiritual, emotional, and social, as well as physical aspects of health. "Candidates," as the trainees are known, come from mainly a theological background (i.e., they are trained and/or working as Christian workers in their villages and typically have little knowledge of health). In the North Indian state of Uttarakhand, the Community Health Global Network (CHGN) has joined with the Herbertpur Christian Hospital $(\mathrm{HCH})$ and Landour Community Hospital (LCH) to support candidates in its region. CHGN has secured funding to employ a coordinating facilitator whose role includes both technical and pastoral support for the candidates, and to provide additional support to up to 40 candidates per year. Over 250 candidates have graduated from the course with funding through $\mathrm{CHGN}$.

The present study sought to determine some of the outcomes of the CLHTC course for the candidates and their communities in Uttarakhand. It aims to contribute to the literature on the outcomes of training CHWs, concerning the trainees and the communities they serve. ${ }^{2}$

\section{Methods}

The study was undertaken during November 2016 in Uttarakhand state, North India and consisted of a triangulation of semi-structured interviews and focus group discussions. A research assistant from a global health institute in Australia conducted the semi-structured interviews with the CHGNemployed coordinating facilitator, the secretary of the CLHTC initiative within CHGN, the president of CHGN, and three managers of course graduates employed by the organisation "NGO1" (a small organisation that conducts community development work among remote districts outside of Mussoorie). The interviews were conducted in English. Four focus group discussions were conducted with graduates from either $\mathrm{HCH}$ or $\mathrm{LCH}$ (14 participants). Focus group discussions were held in Hindi at the training site at $\mathrm{HCH}$ (two) or in communities of service (two). Three focus group discussions had live translation (Hindi to English) through an interpreter, and the fourth focus group's discussion was audiorecorded for subsequent oral translation by an interpreter with transcription by the researcher.

Graduates who lived within appropriate reach of the study sites were nominated for participation by the coordinating facilitator of the course or managers of NGO1. The latter recruited the participants by telephone invitation, to a total of five available persons.

Following translation and transcription of the interviews and discussions, a grounded theoretical approach was used in undertaking a thematic analysis of the interviews and discussions. This involved generating initial codes, searching for themes among codes, reviewing themes, defining and naming themes, and producing the final report. The first author (NB) initiated the initial codes and sub themes, and the second author (NG) reviewed the themes. Together, NB and NG determined the final meta-themes and sub-themes produced in the report.

The study was considered exempt from a requirement for ethical review.

\section{Results}

During implementation of the study, some additional participants manifested, some did not show, and an additional source of data became available. The changes were as follows: a fifth 
discussion group was scheduled for several graduates, but only one (male) could attend, so this was conducted as an interview. At one focus group discussion, three community health volunteers (not trained through the CLHTC course but by a graduate thereof), including one government-trained ASHA, were present in addition to the female graduate. Only the graduate's remarks were included in this study. In addition, a graduation ceremony for candidates completing the 2016 course was held during the time of the study. Therefore, the graduation speeches were audio-recorded and subsequently livetranslated and transcribed, to serve as supplementary textual data. This data included recordings of five of the participants of one focus group discussion.

Graduates had between approximately nine months to four years of practice experience on which to draw to inform their sharing experiences and observations.

The thematic analysis revealed four meta themes, each with a number of sub-themes, as follows: (1) the course delivery is effective in its design and delivery, and particularly in view of the role of the coordinating facilitator; (2) the course has impact at the community level, with graduates' practices matching the objectives of CMC, Vellore, extending basic healthcare to rural and disadvantaged communities, and embedding them in the community as holistic healthcare workers; (3) the course facilitates health system strengthening through the multiplication of skills, collaborating with existing authorities, and advocating for higher quality in professional practice; and, (4) graduates lack ongoing support and training. The findings are presented under these four headings.

\section{The Course Delivery Is Effective}

\section{The CLHTC course content is comprehensive, delivered in a uniquely practical manner}

Several interview respondents spontaneously commented on the "impressive" (SSI4) range of topics covered in the course manuals. Encapsulating these comments, one interviewee said, "The manuals are simple and effective... very easy to follow... The method of training is very good." (SS2) Another interviewee said, "[CLHTC] enhances the work of those whose work is faith-based, to understand health in a scientific way." (SSI1) One female graduate has developed a curriculum for training community health volunteers in a number of surrounding villages based on the content of the CLHTC.

It was found that the delivery of the content constituted a key strength of the program. One interviewee noted that the combination of theory, curriculum, and "hands-on" opportunities with "assignments to complete in the field" made the CLHTC "a good package."(SSI1) Underscoring the effectiveness of the practical mode of knowledge and skills transfer, several candidates alluded to the inferiority of their prior education or training in comparison to the CLHTC course. Further comments were as follows:

- Whatever I've learnt, I've been able to apply it in my work and in my family. (GS1)

- Whereas community health volunteers have experience, CLHTC graduates have training... [the training] has made them qualified. (SSI2) Coordinating facilitator, a "pillar" upholding the course

The CHGN-employed Coordinating Facilitator was mentioned by many respondents as being of key importance in the successful completion of the course:

- I really enjoyed [the Coordinating Facilitator's] way of teaching, her approach she's a good teacher. The two trainers were so good. Not only in the classroom but also outside class, they looked out for us and followed up with prayer. (FGD11)

- [Her] role has been crucial. She has been very supportive, but had she not been there we wouldn't have been able to complete the course. She is strict, but she equally cares for and loves us. (FGD32)

- We can call [her] if we're stuck and don't know what to do. She always makes herself available. She is strict, but loving. (FGD34) 
Three respondents independently told the story of a trainee in the 2016 cohort who managed to deliver a baby on the side of the road, with thanks to the availability and support of the coordinating facilitator by telephone.

\section{The Course has Impact at the}

\section{Community Level}

\section{Graduates are active in all intended practices}

CMC intends for graduates to be active in: health education; illness prevention through health promotion; follow-up and care of mother and child; healthcare for "common ailments"; first aid; followup care of patients on long-term treatments; referral; and health advocacy. Across all focus group discussions each of these activities was cited, the most common being health education (through prevention and awareness raising) and healthcare provision (in the form of first aid, diagnosis, treatment or referral).

Activities associated with health education included calling groups of villagers together for lessons, teaching large school groups, and teaching at village meetings. One male respondent moved strategically through schools in his area. He said, "Our target is to reach all the schools in three months. The students are from all backgrounds - low caste, high income. We hope that they'll take this information home and act as change agents that will have an impact."(FGD14) Two trainees referred to health "camps" they had run over a two- to three-day period in different regions to raise awareness about "[Tuberculosis], cancer, and general health" among community members (FGD31, FGD34). Two graduates have opened a primary school since completing the course and have the express intention of promoting health among parents as well as the children.

Healthcare provision was typically one-onone, and involved syndromic diagnoses according to logarithms in the course manual, distribution of basic remedies such as paracetamol, rehydration salts and cough syrups, measuring blood pressure or blood glucose, and referring individuals needing further medical attention (some accompanied their patients to the referred facility).

\section{Quality, holistic healthcare is extended to remote areas}

The majority of course participants live and serve in remote locations where access to healthcare is otherwise non-existent outside of a several-hour journey to a hospital. Therefore, the presence of CLHTC graduates in the community extends the availability of care to remote locations, providing "timely help for those who are sick..." (SSI1), which is holistic in its approach.

- People now have someone to go to. It's a big help. (SSI1)

- We are creating a very good grassroots change agent with a good understanding of health and holistic health... [They] address misconceptions and harmful practice in the community. (SSI1)

The CLHTC course encourages candidates to integrate prayer into their consultations. Several candidates reported offering prayer before or after diagnosing a patient and/or treating him/her. One respondent said that some patients appreciate the prayer so much that they return for prayer alone.

\section{Villagers are mobilised to seek healthcare}

Having CLHTC-trained workers in the community has a mobilising effect on community members such that they are beginning to seek healthcare treatment and advice. Respondents said that villagers were making careful observation of the effects of consultation/treatment on the graduates' patients, and acting accordingly. That is, if a patient's wellbeing was perceived by villagers to have improved after consultation, they would consider consulting the graduate too. Some villagers who received the graduate's services would refer or accompany fellow villagers to see them. In two locations, respondents reported a general growth in attendance for immunisation and antenatal care in their area. This was not verified by means of additional data collection from health services or information management systems. 


\section{Relationships with community members are strengthened}

Completion of the course has had a notable impact on graduates' relationships with community members, in particular causing them to gain respect, appreciation, and the confidence of villagers.

- $\quad$ People in my village respect me now. I've become more important to them. When I was away for training, they knew where I was, so they expected me to return with new skills. Only a few trusted me at first. They testified that I was reliable and now everyone comes to me. Now they come every day. (FGD51)

- $\quad$ People appreciate that I take BP but don't charge... People feel more comfortable with me than the roadside doctor. We're loving, caring and invite them into our home. We want to look after them... They also call to say 'thank you'. (FGD22)

- I observe that anyone who gives any counselling does it for money. Life is shortif we give counsel to someone that influences their worldview, everything is worthwhile. People start to notice that we provide counsel without seeking any reward for ourselves. It's for the benefit of the community. (FGD13)

One manager noted that when encountering opposition, his graduates "press on and let the results of their work speak for themselves." (SSI2)

\section{The Course Facilitates Health System}

\section{Strengthening and Advocacy}

\section{The CLHTC course has a multiplicative effect}

As previously noted, one female graduate has undertaken to train community health volunteers in several villages. She holds regular training sessions for up for forty volunteers (total over 200 female trainees), thus transferring her knowledge through the CLHTC curriculum, and providing a point of contact and support to the volunteers. Two of her fellow graduates are involved in the training and follow-up of those trainees. Other graduates also train health volunteers, underscoring both the multiplicative effect of training candidates effectively and the associated extension of health education and basic healthcare provision to remote villages. One graduate mentioned that he had trained his brother to help villagers when they called during his absence.

\section{Cooperation with local/government service providers is enhanced}

Respondents spoke of the establishment and improvement of relationships with key community players, including government health workers / volunteers as well as village heads and other local authorities.

Three respondents mentioned that they have become involved in the government-mandated health and sanitation committee of their village or area. Two of these said that due to their joint influence, the local committee had re-formed and monthly meetings had begun with good support from local authorities, police, education and religious sector representatives, and others.

For graduates associated with NGO1, their rapport with the government-supported ASHAs, Auxiliary Nurse Midwives (ANMs), and local Anganwadi (government-sponsored child care and mother care centre) workers has been enhanced.

- $\quad$ The ANM, ASHA, the village head, and head of district appreciate our work. That's why they continue to send people to us. (FGD42)

In addition to endorsing graduates' practices, these government workers willingly collaborate with them. For example, when the ANM is scheduled to visit the village for immunisation or maternal and child health clinics, she notifies the ASHA who in turn informs the graduate, and together they rally villagers to attend the services.

The CMO of the district where NGO1 works affirmed the graduates in their work, and one respondent said that the head of her village was "very happy with our work, very supportive, (told) us we're doing good for the village, and the people (were) keeping well." (FGD42)

CLHTC graduates advocate for strengthened professional practice in health 
By virtue of their work ethic, some graduates are having an impact on the conduct of health practitioners. Respondents from NGO1 reported that their collaboration with government reproductive, mother, and child health workers had positively influenced those workers' practices:

- $\quad$ The ANMs used to work dishonestly, just filling their registers without doing the work. When they came to work alongside us, we urged them to fill in their registers only when the baby had been vaccinated. Now they're working honestly. By our example, we demonstrate the way to truly follow the plan set out for ASHAs... visit newly-marrieds, and so on. We tell them that the leaders may not be watching but the Big God is. (FGD21)

Another graduate stressed the challenge and simultaneous opportunity of working in the context of unqualified or unauthorised providers:

- $\quad$ There are quacks everywhere-they feel threatened by us. The challenge is to develop a relationship with them! Sometimes they listen to what we say, agree that, 'yes, you are right' but don't change. (FGD11)

A male graduate reported having roused some conflict among local authorities due to his calling health practitioners to account in an assignment:

- I conducted a survey on HIV/AIDS. Somehow the media got hold of [my report] and the local officials got angry because it spoke out against them. I learned that what we learn and what we do is a little bit different... Local health providers used to be selling iron-folate tablets intended for pregnant women on the market. Now, at least, the pregnant women are receiving them. (FGD13)

\section{The Course Could Be Even More Effective}

\section{Improved referral linkages needed}

Many respondents expressed a need for better referral pathways to doctors at the nearest facility.
Stronger linkages would also legitimise the advice and practice of the graduates.

- We need a contact person and to know where/to whom to send the patient-a lot of villagers ask which doctor they should go to and we don't have an answer. (FGD32)

- We need a referral system so we can refer patients to a doctor directly - a lot of patients ask us for medicines and assistance to be taken to the hospital. (FGD31)

- Linking to doctors in the hospital (contact number) to be able to tell a community member, 'I don't know, but I can ask and let you know' because they have access to a doctor who can advise them. (SSI1)

\section{More systematic follow-up support and training needed}

The relationship between ASHA workers and graduates associated with NGO1 has given rise to an arrangement whereby the ASHA workers keep graduates abreast of any government policy updates. In order to keep abreast of these and general developments in health, however, many respondents expressed their need for follow-up support postgraduation.

- [We need] Occasional checks from CLHTC (say, once every six months) to help us know we're practising well and keeping confident, and to check on my records... The point is to keep us alert... Not from the Chief Medical Officer, because CLHTC are my people and they're coming to check on me-the people will see that my people are checking up. (FGD41)

- [We need] Some practical experience with a doctor to observe what we do. (FGD12)

- "A smartphone application," an "SMS reminder" service and/or "a quarterly magazine" from CMC. (SSI1)

Nearly all respondents referred to the lack of refresher courses. Some added that graduates were in need of opportunities for information updates and case discussion amongst peers. 
- Everything is changing-medical guidelines, government regulations on money-so it's important to [be] refreshed and updated. We need to learn about the changes... Every six months. (FGD13)

\section{Discussion}

The CLHTC training curriculum was found to correspond to many of the standards outlined by Lehmann and Sanders and Oliver et al., and CLHTC graduates generally mirrored international understandings and definitions of CHWs. ${ }^{1,2}$ Respondents were highly appreciative of the course and indicated that the CLHTC course, in particular through its provision of a comprehensive training package, equipped candidates to serve their communities effectively and integrate with existing health services. Their views echoed those of CHWs studied by Oliver et al., who reported that their training had not only provided "health messages for them to communicate, but also techniques to demonstrate, discuss and collaborate." ${ }^{2}$ (p. 12) Internationally, the scope of CHW practice is broad, however, depending in part on the resources behind the program. Whereas many programs offer a basic training course and ongoing participation in a designated $\mathrm{CHW}$ initiative, this is rather a course that produces graduates whose practice does not form part of such a system.

With respect to the training component, the findings suggest that the CLHTC course is potentially distinct from other didactic courses, in view of the availability, diligence, moral, and technical support of the coordinating facilitator. Playing a key role in the preparation of candidates, the appointment of this person can be considered a strength of the current CLHTC program in Uttarakhand.

CLHTC graduates were found to be practicing across the range of activities intended by CMC and most CHW programs. In citing both preventive and curative activities as being routine practices, graduates indicated that they struggled less than other CHWs with the tension of balancing the two forms of care ${ }^{7}$. Moreover, CLHTC graduates' activities comprised pastoral care (counselling, prayer, other) in addition to the common role description of a CHW. As indicated by at least one respondent, some villagers valued this spiritual support, returning expressly for prayer, which corresponded to findings in a previous study of the course and the generally accepted notion in India of health comprising the spiritual as well as the physical. ${ }^{8}$ A possibly unique quality to the CLHTC course is that of the proactive transfer of health knowledge and skills, which is evident among graduates in both Uttarakhand and other parts of India. ${ }^{8}$ This multiplication effect indicates that graduates have indeed become change agents, as per the CLHTC course motto. Apart from encouraging candidates to visit various gathering places (such as village meetings, schools) and comprising communication and presentation skill components, the course does not have a lesson on multiplication per se, and hence it is the graduates who determine what form and extent these activities will take. In terms of the sustainability of that multiplication, it would seem that there is a strong degree of sustainability built into the however-informal model of respondents who were committed to providing regular training to local health volunteers.

There was evidence in Uttarakhand that CMC had fulfilled its objective to produce graduates who could contribute to meeting the health needs in underserved areas of their residence and outreach. By their own inference, graduates had been making an impact on villagers' health literacy and healthseeking behaviours. Both this social mobilisation and the building of trust were un-quantifiably important impacts of $\mathrm{CHW}$ programs, which were evident in the findings, including growing access to graduates' and government primary healthcare services. ${ }^{9}$ The finding of increased uptake of immunisation was consistent with a Cochrane review of $\mathrm{CHW}$ effectiveness and supportive of efforts to improve routine immunisation coverage in India, though was not verified through external sources such as health service data. ${ }^{10,11}$ Thus, a 
quantifiable degree of impact on community was not obtained, which may lend to an extension of the study including, for example, a review of graduates' registers, numbers of referrals made and completed, and health service uptake data.

WHO understands that training CHW distinguishes ("separates") lay persons from their communities. ${ }^{12}$ Indeed, candidates had cause to interact with villagers in new ways and thus had gained a new sense of identity in their community. Participation in the course had also had an overall positive impact on candidates' self-confidence as well as their relationships with family members and villagers, echoing the experience of ASHAs in Manipur and CHWs abroad. ${ }^{2,3,7}$

The activities of CLHTC graduates had also engendered a strengthening of relationships with local service providers, mainly in health but also in local governance roles. This was achieved in part through their activity within community structures and institutions: participating in (or initiating) village meetings, collaborating with local health practitioners, and establishing links with local schools. In their interface between the health system and the community, the graduates had gained both a good reputation and opportunities for advocacy. The example of graduates encouraging ANMs and ASHAs in the quality of their work implies that the attitudes, approaches and practices of the CLHTC graduates have had direct and indirect impacts on the performance of those in their sphere of influencelocal health practitioners and village authorities, in particular. This is an achievement that the ASHA program has not realised at scale. ${ }^{3,13}$

Having developed "new beliefs and expectations about health and healthcare," CLHTC graduates have also gained an awareness of the extent and impacts of fraudulent practice. ${ }^{12}$ Respondents noted that practicing alongside "quacks," as they called them, had created conflict with those providers and that villagers received conflicting messages about health and healthcare. Unqualified practice is widespread across India, and practicing in such a context will likely be a persistent challenge to CLHTC graduates; ${ }^{14}$ hence, their work in this context contributes to interventions against that dimension of the health system.

Regardless of the level of care or standards respondents perceived some health providers applied, there was a clear emphasis on the need for formal links to health professionals. Respondents believed that establishing this contact was important for the affirmation of their new role, for the provision of ongoing support, and for making appropriate referrals. In addition to the provision of support and collegiality, it was also a call for supervision. Supervision has been tied to good decision-making by CHWs, motivation/morale, and retention levels and productivity, and indeed, it is widely recommended for CHWs to be supported by the health system. ${ }^{12,15}$ However, the interest of health personnel in supervising CHWs was often minimal and an early study found that the influence of the community was, in fact, greater in assuring CHW motivation and performance than supervision by the health system. ${ }^{1,7,16}$ Therefore, an appropriate literature review and contextual analysis of the various influencing factors need to be conducted before establishing any post-graduation support structure.

Lastly, respondents placed equal emphasis on the need for refresher courses and other forms of follow-up contact with the program. Lehmann and Sanders note that across all literature, "there is agreement on one matter: that continuing or refresher training is as important as initial training." (p. 4) CMC has extended an invitation to graduates to attend refresher training in Vellore every two years, but it seemed that the participants in this study had not known about or used the opportunity. Both supervision-based and recognition-based incentives can help CHWs feel supported and motivated, and post-graduation support can take on innovative forms, such as use of mobile technology, as suggested by one of the respondents. ${ }^{7,15,17}$ It is important to note, meanwhile, that CHW motivation is optimised when multiple incentives are rolled out over time. $^{7}$ 


\section{Limitations}

The study did not have the capacity to explore responses across a representative proportion of graduates. Thus, the involvement of graduates who were available for participation and within access of the researcher may constitute selection bias. However, the reports and themes were largely consistent between discussion groups and interviewees, and data saturation was achieved in that the responses became consistent and somewhat predictable.

There is, meanwhile, a possibility of social desirability bias with participants tending to report mostly positive aspects of the CLHTC, their role, and its impact. This possibility could have been accentuated in that independent translators and facilitators were not always available.

The evaluation was limited in that our methodology did not focus on quantitative data in assessing indicators such as hospitalizations and mortality. This does not invalidate the qualitative approach study but does indicate room for additional quantitative studies.

\section{Conclusion}

This study has found that the CLHTC course is presently meeting the objectives set by CMC and producing graduates that correspond to the dominant conceptualisation of a community health worker. The course is not only having an impact on the health situation in Uttarakhand, but also on course candidates and those who are in their sphere of influence where they live and practice, including health providers. The course content and delivery in Uttarakhand are reportedly of excellent quality, particularly in light of the Coordinating Facilitator's technically and morally supportive role, and produce well equipped graduates who are highly motivated to meet the "immense health need" of the populations they serve (as per the objective of the course). Following graduation, course candidates practice across the range of prescribed activities, balancing preventive and curative measures well. As intended for any CHW, CLHTC graduates establish or further their relationships with their community, both its members and its authority figures, and effectuate social mobilisation. The CLHTC course has led to largely positive outcomes for candidates as well as for their communities and local community structures. Weaknesses of the program were the lack of integration with formal health structures and limited opportunities for post-graduation contact including refresher training.

\section{References}

1. Lehmann U, Sanders D. Community health workers: what do we know about them. The state of the evidence on programmes, activities, costs and impact on health outcomes of using community health workers. Geneva: World Health Organization; 2007 Jan:1-42.

2. Oliver M, Geniets A, Winters N, Rega I, Mbae SM. What do community health workers have to say about their work, and how can this inform improved programme design? A case study with CHWs within Kenya. Global Health Action. 2015 May 22;8. https://doi.org/10.3402/gha.v8.27168.

3. Saprii L, Richards E, Kokho P, Theobald S. Community health workers in rural India: analysing the opportunities and challenges Accredited Social Health Activists (ASHAs) face in realising their multiple roles. Human resources for health. 2015 Dec 9;13(1):95. https://doi.org/10.1186/s12960-0150094-3.

4. Patel V, Parikh R, Nandraj S, Balasubramaniam P, Narayan K, Paul VK, Kumar AS, Chatterjee M, Reddy KS. Assuring health coverage for all in India. The Lancet. 2015 Dec 18;386(10011):2422-35. https://doi.org/10.1016/S0140-6736(15)00955-1

5. Bajpai V. The challenges confronting public hospitals in India, their origins, and possible solutions. Advances in Public Health. 2014 Jul 13;2014. https://doi.org/10.1155/2014/898502.

6. Ministry of Health and Family Welfare. Rural Health Statistics 2014-15. New Delhi: Statistics Division; 2015.

7. Bhattacharyya K, LeBan K, Winch P, Tien M; United States Agency for International Development (USAID). Community health workers: incentives and disincentives: how they affect motivation, 
retention, and sustainability. Arlington, (VI): USAID, Basic Support for Institutionalizing Child Survival Project (Basics II); 2001 Oct 8. 52 p.

8. Butcher N, Sitther A, Velavan J, John E, Thomas $\mathrm{MC}$, Grills N. Evaluation of community health worker training course effectiveness in India. Christian Journal for Global Health. 2016 Nov 8;3(2):18-26. https://doi.org/10.15566/cjgh.v3i2.142

9. Walker DG, Jan S. How do we determine whether community health workers are cost-effective? Some core methodological issues. Journal of Community Health. 2005 Jun 1;30(3):221-9. https://doi.org/10.1007/s10900-004-1960-4

10. Lewin SA, Dick J, Pond P, Zwarenstein M, Aja G, van Wyk B, Bosch-Capblanch X, Patrick M, Walt G, Morrow Rh, Lewin S. Lay health workers in primary and community health care: Cochrane systematic review. Commentary. International Journal of Epidemiology. 2005;34(6):1250-3.

11. Patel AR, Nowalk MP. Expanding immunization coverage in rural India: a review of evidence for the role of community health workers. Vaccine. 2010 Jan 8;28(3):604-13. https://doi.org/10.1016/j.vaccine.2009.10.108

12. Kahssay HM, Taylor ME, Berman P; World Health Organization. Community health workers: the way forward. Geneva: World Health Organization;1998.

13. Fathima FN, Raju M, Varadharajan KS, Krishnamurthy A, Ananthkumar SR, Mony PK.
Assessment of 'Accredited Social Health Activists'-A National Community Health Volunteer Scheme in Karnataka State, India. Journal of health, population, and nutrition. 2015 Mar;33(1):137.

14. Krishna D Rao. Human resources for health in India: current challenges and policy options. In: IDFC Foundation. India Infrastructure Report 2013-14: The Road to Universal Health Coverage. Orient BlackSwan; 2014. p. 251-264.

15. Jaskiewicz W, Tulenko K. Increasing community health worker productivity and effectiveness: a review of the influence of the work environment. Human resources for health. 2012 Sep 27;10(1):38. https://doi.org/10.1186/1478-4491-10-38

16. Bhutta ZA, Lassi ZS, Pariyo G, Huicho L. Global experience of community health workers for delivery of health related millennium development goals: a systematic review, country case studies, and recommendations for integration into national health systems. Global Health Workforce Alliance. 2010;1:249-61.

17. Funes R, Hausman V, Rastegar A, Bhatia P, Dalberg Global Development Advisors. Preparing the next generation of community health workers: the power of technology for training. Cork, Ireland: Iheed Institute; 2012 May. 59 p.

Peer Reviewed

Competing Interests: None declared.

Correspondence: Nicole Butcher, Nossal Institute of Global health, University of Melbourne, Australia. butcher.nicole@gmail.com

Cite this article as: Butcher N, Grills N. Impacts of community lay-leader health worker training and practice (Uttarakhand, India). Christian Journal for Global Health. July 2017; 4(2):43-52.

https://doi.org/10.15566/cjgh.v4i2.162

(C) Butcher N, Grills N. This is an open-access article distributed under the terms of the Creative Commons Attribution License, which permits unrestricted use, distribution, and reproduction in any medium, provided the original author and source are properly cited. To view a copy of the license, visit http://creativecommons.org/licenses/by/4.0/

www.cjgh.org 